\title{
Intestinal Transport of Glucose and Amino Acids in Experimental Uremia
}

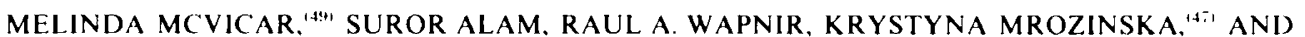 \\ FIMA LIFSHITZ \\ North Shore University Hospital, Department of Pediatrics, Manhasset, New York, and Cornell University Medical \\ College, Department of Pediatrics. New' York. New' York. USA
}

\begin{abstract}
Summary
The effects of chronic uremia on the intestinal transport of amino acids and glucose were assessed by an in vivo perfusion technique in young uremic rats and pair-fed controls. The experimental rats were rendered uremic by a modification of the conventional $5 / 6$ nephrectomy, and control animals were sham operated. All intestinal perfusions were performed 4 to 6 wk after completion of surgical induction of uremia. The mean BUN of the experimental group at the time of evaluation of intestinal transport was 79 $\pm 18 \mathrm{mg} / \mathrm{dl}$ (mean \pm S.E. $)$ compared to $23 \pm 9 \mathrm{mg} / \mathrm{dl}(P<0.02)$ in control animals. A 20-cm-long segment of proximal jejunum was perfused in vivo with Krebs-Henseleit buffers containing amino acids and carbohydrates with ${ }^{14} \mathrm{C}$-and ${ }^{3} \mathrm{H}$-labeled tracers. The jejunal absorption of tyrosine was significantly increased in uremic rats: $5.63 \pm 0.42$ as compared to $3.47 \pm 0.28 \mathrm{nmoles} / \mathrm{min} \times \mathrm{cm}$ in the controls $(P<0.001)$. Similarly, the absorption of phenylalanine was increased in the uremic rats; $5.79 \pm 0.41$ versus $3.74 \pm 0.32$ nmoles $/ \mathrm{min} \times \mathrm{cm}$ in the control rats $(P<0.001)$. Confirmation that increased phenylalanine absorption represented a true lumento-blood flow was obtained by measurement of $\left.\right|^{3} \mathrm{H} \mid$ phenylalanine in blood drawn from the aorta after $60 \mathrm{~min}$ of perfusion. The blood count in uremic rats was $2,307 \pm 257 \mathrm{dpm} / \mathrm{ml}$ versus $1173 \pm 172$ $\mathrm{dpm} / \mathrm{ml}$ in controls $(\boldsymbol{P}<\mathbf{0 . 0 1})$. The absorption of glucose along the jejunum was also increased in the uremic rats over the controls both at 4 and $40 \mathrm{mM}$. At $4 \mathrm{mM}$, the absorption in uremic rats was $27.79 \pm 1.84$ versus $21.02 \pm 1.66 \mathrm{nmoles} / \mathrm{min} \times \mathrm{cm}(P<0.01)$ in controls. At $40 \mathrm{mM}$, the values were $228.5 \pm 16.3$ and $170.9 \pm$ $16.9 \mathrm{nmoles} / \mathrm{min} \times \mathrm{cm}$, respectively $(P<0.02)$. In contrast, the absorption of histidine and alpha-aminoisobutyric acid was not significantly different between uremic and control animals. The alterations in jejunal transport were associated with a decreased incorporation of $\mathrm{I}^{3} \mathrm{H} \mid$ phenylalanine into protein in the cell membrane-rich portion of intestinal mucosal scrapings $(43.7 \pm 4.7 \mathrm{nCi} /$ g protein versus $94.2 \pm 13.1 \mathrm{nCi} / \mathrm{g}$ protein in controls; $P<0.01$ ). There was also secretion of glucose from blood-to-intestinal lumen, which was significantly greater in uremic than in control animals: $1.41 \pm 0.16$ versus $0.87 \pm 0.05$ nmoles $/ \mathrm{min} \times \mathrm{cm}(P<0.01)$. These results are consistent with an alteration of the integrity of the jejunal mucosa in uremia which affects its permeability and alters the transport of nutrient.
\end{abstract}

\section{Speculation}

The decreased incorporation of phenylalanine into membranebound material of the jejunal mucosa and the increased blood-tolumen flux of glucose in uremic rats may indicate a defect in the integrity of the intestinal mucosa. This may be associated with an altered premeability, which facilitates increased intestinal absorption of solutes. These kinds of changes in uremia seem to be different in pathogenesis from those induced by malnutrition per se. The observed changes in jejunal absorption appear to compen- sate for, rather than to contribute to, the malnutrition and growth failure typical of chronic uremia.

Children with uremia frequently have impaired growth which is commonly attributed to their poor nutritional status $(3,14,29)$. Abnormal concentrations of plasma and urine amino acids have been found in uremic children and adults, and some authors have suggested that abnormalities of amino acid metabolism contribute to nutritional and growth deficiencies in uremia $(2,9,10)$. Gulyassy and Aviram (12) found decreased plasma levels of tryptophan in uremic patients compared to normal individuals after oral loading and suggested that intestinal transport of this amino acid was impaired in uremia. Significant failure of reabsorption of amino acids from the proximal renal tubule is known to occur in uremia $(2,12)$. A recent study using rats showed variable effects of uremia on the intestinal transport of leucine (39). This was associated with increased activity of disaccharidases and gammaglutamyl transpeptidase in intestinal brush border preparations of the uremic rats.

Studies of intestinal absorption and of the various factors which affect growth and nutrition in uremic patients are limited by problems of dietary control and heterogeneity among patients. In the current study, we have utilized a model of chronic uremia in rats to explore in vivo whether intestinal absorption of glucose and selected amino acids was altered in this condition. We found increased absorption of phenylalanine, tyrosine, glucose, and 3$O$-methyl-glucose associated with evidence suggestive of increased permeability of the jejunal mucosa.

\section{MATERIALS AND METHODS}

Male Wistar rats weighing 130 to $150 \mathrm{~g}$ were made uremic by modification of the conventional ${ }^{5}{ }_{i}$ nephrectomy (1). In addition to the removal of the upper and lower poles on one kidney during the initial procedure, the lateral cortical tissue of the remaining midportion was also excised. One wk later, contralateral total nephrectomy was performed leaving approximately ${ }^{1} 12$ cortical mass versus the conventional 1 if. Control animals were shan operated and pair fed the same amount of Purina lab chow (4I) as their experimental counterparts had taken the preceding day. This meal was offered late in the afternoon. shortly before the beginning of the rats active cycle to minimize differences which might occur from feeding patterns. Water was available ad libitum. The rats were individually caged, and their weights were recorded weekly. Blood was drawn from the tail vein each wk for determination of blood urea nitrogen (BUN) (42). Studies of jejunal transport were initiated 4 to $6 \mathrm{wk}$ after surgically inducing uremia when the BUN in the experimental group reached at least $60 \mathrm{mg} /$ $\mathrm{dl}$ and did not exceed $110 \mathrm{mg} / \mathrm{dl}$. Rats with BUN levels outside this range were discarded. The mean $( \pm S$.E.) BUN of the uremic rats at the time of intestinal perfusion was $79 \pm 18 \mathrm{mg} / \mathrm{dl}$. whereas in the control animals it was $23 \pm 9 \mathrm{mg} / \mathrm{dl}(P<0 .(02)$. Uremic 
rats had a plasma creatinine of $1.40 \pm 0.08 \mathrm{mg} / \mathrm{dl}$ versus $0.55 \pm$ $0.05 \mathrm{mg} / \mathrm{dl}(P<0.00 \mathrm{l})$ in controls. The creatinine clearance $(5)$ measured in 12 control animals during the $24-\mathrm{hr}$ period before intestinal perfusion studies was $0.98 \pm 0.03 \mathrm{ml} / \mathrm{min}$ versus $0.35 \pm$ $0.05 \mathrm{ml} / \mathrm{min}$ in 17 uremic rats $(P<0.001)$. Guanidinosuccinic acid (23) in the pooled blood sample of four uremic rats was 1.6 $\mathrm{mg} / \mathrm{dl}$ compared with $0.4 \mathrm{mg} / \mathrm{dl}$ in the pooled sample from the control rats. The urine values were 0.92 and $0.25 \mathrm{mg} / \mathrm{dl}$, respectively, for uremic and control pooled samples. The four-fold increase over normal values of the uremic toxin guanidinosuccinic acid in blood and urine samples is consistent with previously published studies showing a similar increase in uremic rats and humans (31) and further confirms the adequacy of our model.

The transport of selected amino acids and glucose from lumento-blood as well as from blood-to-lumen was studied in vivo. The technique has been described fully elsewhere (35). In brief, the rats were anesthetized with $1.5 \mathrm{mg} / \mathrm{kg}$ urethane administered IP, the abdominal cavity was opened by a midline incision, and the small intestine was cannulated below the ligament of Treitz. A 20$\mathrm{cm}$-long segment was utilized for perfusion, and intestinal contents were washed with two $10 \mathrm{ml}$ portions of $0.15 \mathrm{M} \mathrm{NaCl}$. The proximal end of the intestinal segment was attached to a Harvard peristaltic pump (43) and perfused at the rate of 0.20 to $0.24 \mathrm{ml} /$ $\mathrm{min}$. The solutions used for perfusion of the jejunal segment were Krebs-Henseleit bicarbonate isotonic buffers with $1 \mathrm{mM}$ of either phenylalanine, tyrosine, histidine, alpha-aminoisobutyric acid, and 3-O-methyl-glucose. Glucose at either 4 or $40 \mathrm{mM}$ concentration was also included in some of the buffers. Tracer amounts of these substances (44), uniformly labeled with ${ }^{3} \mathrm{H}$ or ${ }^{14} \mathrm{C}$ were added to a level of approximately $20,000 \mathrm{dpm} / \mathrm{ml}$. Polyethylene glycol, molecular weight, 3000 to 3700 (45), a nonabsorbable marker, was used in each experiment to control for water transport and was added to the buffer at a concentration of $6 \mathrm{~g} /$ liter. The solution was maintained isotonic by adjustment of $\mathrm{NaCl}$. The buffer was bubbled with $\mathrm{O}_{2}: \mathrm{CO}_{2}(95: 5)$, and its temperature was maintained at $37^{\circ} \mathrm{C}$. Each rat was perfused with two buffers, each of them containing a test amino acid and carbohydrate. The sequence of perfusion was randomized. After a 45-min equilibration period for each buffer, perfusates were collected every $15 \mathrm{~min}$ for one $\mathrm{hr}$.

The amount of polyethylene glycol in the perfusion samples was determined by turbidimetry (21). The concentration of amino acid and glucose in the perfusate was determined by isotope dilution. Tritium was counted with an efficiency of at least $20 \%$ and ${ }^{14} \mathrm{C}$ with an efficiency better than $50 \%$ as determined by an external source reference and against quenched standards. All samples were counted with a statistical error lower than $1 \%$ and a probability better than $99 \%$ in a Beckman LS-230 liquid scintillation counter.

The transport of amino acids and carbohydrates was calculated by determination of their concentrations in pre- and postperfusion buffers after correction for water transport. Another measure of lumen-to-blood flow was estimated by determining the counts of $\left[{ }^{3} \mathrm{H}\right.$ ]phenylalanine and ${ }^{14} \mathrm{C}$-labeled 3 -O-methyl-glucose in blood drawn from the aorta at the end of the experiment. These results were expressed as nmoles $/ \mathrm{min} / \mathrm{cm}$ of jejunum and $\mathrm{dpm} / \mathrm{ml}$ of blood, respectively. In experiments directed to measure blood-tolumen flow of glucose, Krebs-Henseleit bicarbonate buffers containing no glucose were perfused under the conditions described above. Glucose in the effluent buffer was then determined by a glucose oxidase method (46). The differences between the means of the experimental and control groups were compared using the Student's $t$ test $(8)$ and are expressed as means \pm S.E.

\section{RESULTS}

The mean weight gain ( \pm S.E.) after 5 wk of uremia induced by surgical removal of about $90 \%$ of the total renal mass was 53.8 $\pm 6.1 \mathrm{~g}(N=19)$ for the experimental animals and $84.2 \pm 6.2(N$ $=15)$ for their pair-fed controls $(P<0.001)$. The weight gain of the controls was limited by the reduced food intake which was matched to the ad libitum intake of the anorexic uremic rats. However, the weight achieved by the controls was higher than in experimental rats due to decreased food efficiency in the latter. The uremic animals had a wasted appearance and exhibited sparse and coarse fur. They frequently had muscle twitching and tremors whereas their pair-fed controls had none of these findings. Macroscopically, the intestinal mucosa of the uremic rats did not appear different from that of controls in the whole or cut jejunum, and the mucosal surface was normal in appearance in both uremic and control animals.

The absorption of glucose was found to be significantly greater in the uremic rats compared to their pair-fed, sham-operated controls. Glucose added to the perfusing buffer at the physiologic concentration of $4 \mathrm{mM}$ was absorbed at a significantly greater rate in uremic rats than in controls (Fig. 1). Perfusion of the jejunum with glucose at the higher concentration of $40 \mathrm{mM}$ also showed an increase in absorption in both uremic and control animals. The increase in absorption was proportional to the concentration of glucose in the solutions perfused with a comparable difference at 4 and $40 \mathrm{mM}$ concentrations between uremic and control animals.

The jejunal absorption of tyrosine and phenylalanine from a solution of intestinal perfusate of Krebs-Henseleit buffer containing $1 \mathrm{mM}$ of each radiolabeled amino acid was also significantly increased in chronically uremic rats and was approximately twice the level of that observed in sham-operated, pair-fed control animals (Fig. 2). The absorption rates observed in the control rats

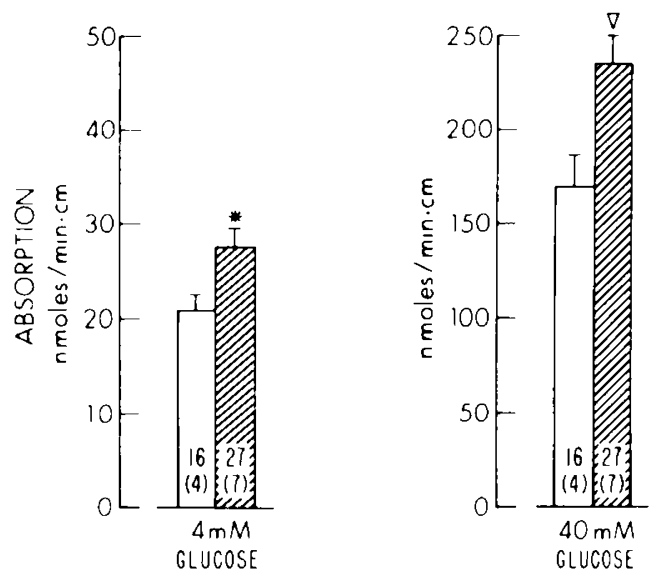

Fig. I. Jejunal absorption of glucose in uremic (hatched bars) and control rats (open bars). Glucose absorption (mean \pm S.E.) is shown for perfusions at 4 and $40 \mathrm{mM} .{ }^{*}, P<0.01 ; \nabla, P<0.02$. Numbers in parentheses, number of rats; numbers above parentheses, number of perfusates analyzed.

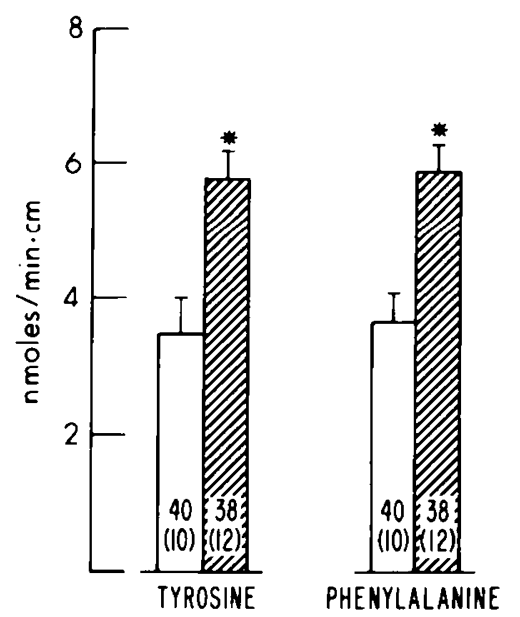

Fig. 2. Jejunal absorption of $1 \mathrm{mM}$ amino acids. Uremic rat values, hatched bars; control rat values, open bars (mean \pm S.E.). Significance and number of determinations as in Figure 1. 
were similar to those found in normal rats in previous experiments in our laboratory with perfusion of tyrosine and phenylalanine in millimolar concentrations.

The differences in jejunal transport rates between uremic and control animals for phenylalanine and glucose truly reflected an increased absorption across the intestinal mucosa because increased levels of $\left[{ }^{3} \mathrm{H}\right]$ phenylalanine and $\left[{ }^{14} \mathrm{C}\right] 3-\mathrm{O}$-methyl-glucose were found in uremic rats in samples taken from the aorta after 60 min of jejunal perfusion as compared to those found in controls. The blood levels for phenylalanine in the uremic rats were almost twice those of controls (Fig. 3), and for the nonmetabolizable analog 3-O-methyl-glucose, the lumen-to-blood flow in the uremic rats was similarly increased in control animals (Fig. 3 ). These data confirm that intestinal absorption, as measured by substrate disappearance from the lumen, represented actual passage of phenylalanine and glucose into the general circulation.

In contrast to the increased intestinal absorption of tyrosine, phenylalanine, glucose, and 3-O-methyl-glucose in uremic rats, there were no statistically significant differences in absorption rates of histidine and alpha-aminoisobutyric acid between uremic and control animals. In these experiments, the mean absorption rate for histidine in uremic animals was $3.75 \pm 0.65 \mathrm{nmoles} / \mathrm{min}$ $\times \mathrm{cm}$ which was similar to the rate of $3.00 \pm 0.51 \mathrm{nmoles} / \mathrm{min} \times$ $\mathrm{cm}$ found in controls. The mean absorption rate of $2.81 \pm 0.55$ $\mathrm{nmoles} / \mathrm{min} \times \mathrm{cm}$ for alpha-aminoisobutyric acid in uremic animals also was not significantly different from the controls which transported alpha-aminioisobutyric acid at a mean rate of $2.62 \pm$ $.53 \mathrm{nmoles} / \mathrm{min} \times \mathrm{cm}$.

Incorporation of $\left[{ }^{3} \mathrm{H}\right]$ phenylalanine into the particulate insoluble protein fraction of the intestinal mucosa of five uremic rats was significantly lower than in four controls (Table 1). However, there were no differences in the incorporation of phenylalanine

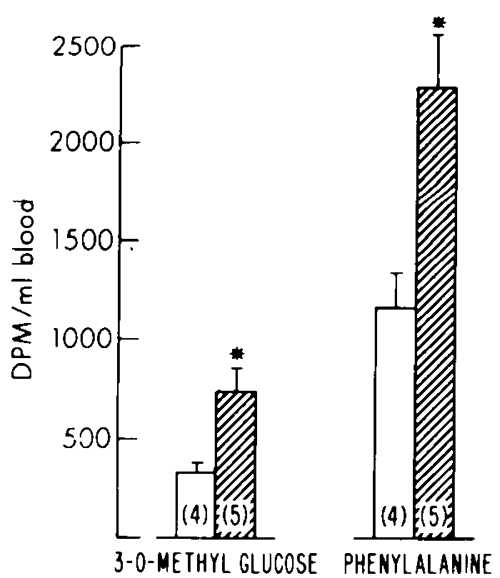

Fig. 3. Lumen-to-blood transport of $\left.\left.\right|^{14} \mathrm{C} \mid 3-O\right)$-methyl glucose and I.$-\left[{ }^{3} \mathrm{H}\right]$ phenylalanine. Mean \pm S.E. Uremic rat values, hatched hars: control rats, open hars. ${ }^{*}, P<0.01$. Numbers in parentheses, number of animals studied.

Table 1. Mucosal protein incorporation of $\left[^{3} \mathrm{H}\right]$ phenylalanine in uremic and control rats

\begin{tabular}{|c|c|c|}
\hline & $\begin{array}{l}\text { Uremic } \\
(N=5)\end{array}$ & $\begin{array}{l}\text { Control } \\
(N=4)\end{array}$ \\
\hline $\begin{array}{l}{\left[{ }^{3} \mathrm{H}\right] \text { Phenylalanine in mucosa }(n \mathrm{Ci} / \mathrm{g}} \\
\text { protein) insoluble protein fraction } \\
=\text { particulate }\end{array}$ & $43.7 \pm 4.7^{1.2}$ & $94.2 \pm 13.1$ \\
\hline $\begin{array}{l}{\left[{ }^{l} \mathrm{H}\right] \text { Phenylalanine in mucosa }(n \mathrm{Ci} / \mathrm{g}} \\
\text { protein) soluble protein fraction }= \\
\text { cytosol }\end{array}$ & $310 \pm 97$ & $295 \pm 42$ \\
\hline
\end{tabular}

into soluble (cytosol) protein. Uremic animals incorporated slightly less than one-half as much $\left[{ }^{3} \mathrm{H}\right]$ phenylalanine into the cell membrane containing insoluble protein fraction, than did the control animals.

The blood-to-intestinal lumen back flux of glucose, was significantly higher in uremic animals (Fig. 4). The uremic rats secreted almost double the amount of glucose from the blood into the intestinal lumen as the controls. Hence, the bidirectional flux of glucose was greater in the uremic rats than in control animals.

\section{DISCUSSION}

The results of this study demonstrate that the jejunal absorption of glucose and certain amino acids is increased in chronic experimental uremia. Uremic rats demonstrated significantly less weight gain than control rats despite similar food intake, suggesting decreased energy efficiency in the uremic rats. This is all the more noteworthy considering the increased intestinal absorption of glucose, tyrosine and phenylalanine which was demonstrated. This is the first report in which increased jejunal absorption of glucose and amino acids in experimental uremia has been shown and the first in which decreased energy efficiency has been demonstrated along with increased absorption. Other investigators $(6$. 33) have reported that uremic rats gain less weight per unit of energy intake than control animals. Our findings support the view that intestinal absorption is not a limiting factor in the availability of nutrients to uremic animals.

The increased absorption of glucose which we found may play a role in the altered glucose metabolism which has long been noted in uremia $(7,13)$. It is likely that as a result of increased absorption greater amounts of glucose would be taken up by the liver. The liver is in turn subject to the increased sensitivity of the glucose-elevating effect of glucagon present in uremia $(4,28,30)$. The increase in glucose absorption was proportionate to the concentration of glucose in the solutions perfused, with comparable differences at 4 and $40 \mathrm{mM}$ between uremic and control animals. This indicates that the same factors which enhanced the passage of glucose solutions across the intestinal mucosal membrane were operative regardless of the concentration of glucose provided that the osmolality was adjusted to be isotonic with plasma.

Absorption of phenylalanine and tyrosine across the jejunum was also shown to be significantly increased in the uremic rats which we studied. Phenylalanine and tyrosine were selected

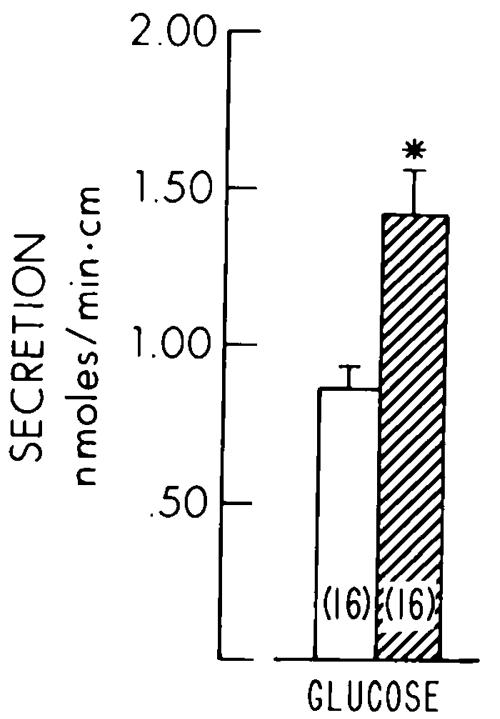

Fig. 4. Jejunal secretion of glucose. The data were obtained from determinations of Krebs-Henseleit buffer perfusates circulated through small intestinal segments. Values for uremic rats, hatched hars, values for control rats, open hars (mean \pm S.E.). ${ }^{*} . P<0.01$. 
among the substances tested because of the consistent finding in uremia of an increased ratio of plasma phenylalanine to tyrosine, related principally to a decrease in plasma tyrosine $(40)$. Recently Jones et al. (16) reported that plasma phenylalanine rose to significantly greater levels in uremic patients than in normal controls following an oral load of phenylalanine. These findings are in agreement with our data which show direct evidence of increased jejunal absorption of phenylalanine in uremic rats. It has been demonstrated in patients and animals with uremia that the conversion of phenylalanine to tyrosine is impaired $(18,19$, 24). Young and Parsons (40) reported that sera from uremic patients produced a $15 \%$ decrease in hepatic phenylalanine hydroxylase activity in normal rats. Although Wang et al. (34) could not confirm this finding, they did show that kidney phenylalanine hydroxylase was significantly decreased in uremic rats. Our finding of increased jejunal absorption of both tyrosine and its precursor, phenylalanine, indicates that malabsorption is not a factor responsible for decreased levels of plasma tyrosine in uremia.

The fact that the absorption of alpha-aminoisobutyric acid and histidine was not altered by uremia can be explained on the basis that. although the neutral amino acids are considered to share a common translocation mechanism, their transport is also mediated by individual membrane carriers which are distinct from the nonspecific carriers $(36,37)$ and may be variably susceptible to the effects of uremia. Histidine is considered an essential amino acid (17), and both increased and decreased plasma levels have been found in uremia $(2,10,17)$. We were not, however, able to demonstrate any difference between control and uremic animals in jejunal transport of this amino acid.

In the studies of Wizemann et al. (39), moderately uremic rats, comparable to those included in our experiments (BUN, 55 to 75 $\mathrm{mg} / \mathrm{dl}$ ) showed decreased absorption of leucine. However, severely uremic rats (BUN, $224 \mathrm{mg} / \mathrm{dl}$ ) had a significantly higher rate of absorption of the same amino acid. The data provided did not allow for correlation of the integrity of the small intestinal mucosa with mucosal enzyme activity and absorption of nutrients.

It has been demonstrated that extreme malnutrition in the absence of uremia results in increased absorption of nutrients across the jejunum $(20,38)$. Lifshitz et al. (20) showed that rats fed low protein, low energy diets for $2 \mathrm{wk}$ had significantly higher glucose absorption than animals fed a control diet. Similarly. Wapnir and Lifshitz (38) demonstrated that jejunal absorption of tyrosine and leucine but not phenylalanine was increased after 4 wk of malnutrition. The increased absorption of tyrosine which we observed was not, however, the mere result of this general effect of severe nutritional restriction because in our experiment the control rats were pair fed the same amount of Purina lab chow taken by the anorexic uremic rats. In addition, the pair-fed controls in our study absorbed glucose, phenylalanine, and tyrosine at rates comparable to those previously found in normal ad libitum fed control rats which were perfused under identical conditions in this laboratory (35). The dissociation between severely malnourished rats which demonstrated normal absorption of phenylalanine and uremic rats which demonstrated increased absorption of this amino acid also argues against our results being an effect of malnutrition

Our finding in the experimental rats of decreased incorporation of phenylalanine into the particulate insoluble fraction of mucosal proteins, generally associated with cell membranes, suggests that uremia interfers with the normal synthesis of structural and func- tional proteins in the intestine. The significantly increased flux from blood-to-lumen demonstrated for glucose in our uremic animals suggests that a permeability defect of the jejunal mucosa was responsible for the enhanced transport which was found. Similarly, Ritz et al. (25) reported a breakdown of the mucosal barrier in the stomachs of uremic dogs. They found significantly increased plasma-to-lumen and lumen-to-plasma fluxes of sodium using Heidenhain pouches.

Structural alterations which might lead to altered cell membrane permeability and decreased protein synthesis have also been described in uremia. Goldstein et al. (11) found electron microscopic abnormalities consisting of shortened villi with a "moth eaten" appearance in the duodenal mucosa of uremic patients. Numerous other reports of mucosal histology in uremia $(15,22,32)$ show congestion and hemorrhage associated with ulcerative and necrotic lesions whenever changes were present. Such lesions were not visible on the mucosal surface of our uremic rats.

Shear (27) evaluated tissue composition and in vivo protein synthesis in uremic rats. RNA content and $\left[{ }^{14} \mathrm{C}\right]$ leucine incorporation parelleling organ weights and protein contents indicated that net protein synthesis was increased in liver and heart, but decreased in skeletal muscle. The author concluded that uremia selectively altered tissue composition and protein synthesis in different organs. In a similar fashion, our results showed that the intestine is another organ in which protein synthesis is decreased when measured by sensitive, direct methods.

The essential findings of this study suggest that alterations in the properties of the cell membrane of the small intestinal mucosa in experimental uremia resulting in increased permeability are responsible for the higher rates of absorption from the intestinal lumen during perfusions in vivo. This is consistent with views of Schultz (26), who pointed out that in certain conditions "leaky" cells in the intestine provide an energy sparing method of solute transport. Such may be the case in experimental uremia. However, the possibility remains that the apparent "leaks" of the intestinal surface can entail the loss of nutrients in a portion of the gut distal to the jejunum with a concomitant decrease of nutritional efficiency for the whole organism.

\section{REFERENCES AND NOTES}

1. Alam, S., Wapnir, R. A., Mrozinska, K., Schneider, S., Lifshitz, F., and McVicar, $M$.: Accelerated chronic renal failure in rats: an improved surgical procedure. Pediatr. Res.. 10: 435 (1976).

2. Betts, P. R., and Greene, A.: Plasma and urine amino acid concentrations in children with chronic renal insufficiency. Nephron. 18: 133 (1977).

3. Betts, P. R., Mann, M. D., and Wolfsdorf, J.: Growth and nutrition of uremic piglets. Pediatr. Res., 10: 937 (1976).

4. Bilbrey, G. L. Faloona, (j. R.. White. M. G., and Knochel, J. P.: Hyperglucagonemia of renal failure. J. ('lin. Invest.. 5.:841 (1974).

5. Bonsnes, R. W.. and Taussky. H. H.: On the colorimetric determination of creatinine by the Jaffee reaction. J. Biol. (hem.. 1.58: 581 (1945)

6. Chantler. C.. Lieberman. E., and Holliday. M. A.: A rat model for the study of growth failure in uremia. Pediatr. Res.. 8: 109 (1974).

7. De Fronzo, R. A.. Andres, R.. Edgar, P., and Walker, W. G.: Carbohydrate metabolism in uremia: a review. Medicine, 52: 469 (1973)

8. Fisher, R. A.: Statistical methods for Research Workers. Ed. 13, pp. 114 (Hafner Publishing (o.. Inc.. New York, 1958).

9. Giordano, C., DePascale, C.. DeSanto, N. G., Esposito, R., Cirilla, D., and Stangherlin. P.: Disorder in the Metabolism of Some Amino Acids in Uremia Proc. Fourth Int. Congr. Nephrol. (Stockholm), 2: 196 (1969).

10. Giordano, C., Esposito, C.. DePascale, C., and DeSanto, N. G.: Dietary treatment in renal failure. Proc. Third Int. Congr. Nephrol. (Wash.). Karger. New York. 3: 214 (1967).

11. Goldstein, D. A., Horowitz, R. E., Petit. S., Haldimann, B., and Massry, S. G Duodenal mucosa in uremic man: effects of $1,25(\mathrm{OH})_{2} \mathrm{D}_{3}$. Kidney Int.. 14 $652(1978)$.

12. Gulyassy, P. F., and Aviram, A.: Evaluation of amino acid and protein requirements in chronic uremia. Arch. Intern. Med., 26: 855 (1970).

13. Hampers, C. L., Soeldner, J. S., Doak, P. B., and Merrill, J. P.: Effect of chronic renal failure and hemodialysis on carbohydrate metabolism. J. Clin. Invest. 4.5: 1719 (1966).

14. Holliday, M. A.: Calorie intake and growth in uremia. Kidney Int., 7 (Suppl. 2): S73 (1975).

15. Jaffee, R. J., and Laing, D. R.: (hanges of the digestive tract in uremua. Arch. Intern. Med., 53: 851 (1934).

16. Jones. M. R.. Kopple, J. D., and Swendseid. M. D.: Phenylalanine metabolism in uremic and normal man. Kidney Int.. 14: 169 (1978).

17. Kopple. J. D., and Swendseid. M. D.: Evidence that histidine is an essential amino acid in normal and chronically uremic man. J. Clin. Invest.. 55: 89 (1975).

18. Kopple. J. D., Wang. M., Vyhmeister, I., Baker, N., and Swendseid, M. E.: Tyrosine metabolism in uremia. In: R. Kluthe, (j. Berlyne, B. Burton: Uremia: An International Conference on Pathogenesis, Diagnosis and Therapy. p. 150 (Georg Thieme Verlag. Stuttgart. 1972).

19. Letteri, J. M., and Scipione. R. A.: Phenylalanine metabolism in chronic renal failure. Nephron. 13: 365 (1974)

20. Lifshitz, F. Hawkins. R. L.. Diaz-Bensussen. S., and Wapnir, R. A.: Absorption of carbohydrates in malnourished rats. J. Nutr., 10): 1303 (1972).

21. Malawer, S. J., and Powell. D. W.: An improved turbidimetric analysis of polyethylene glycol utilizing an emulsifier. Gastroenterology. 53: 250 (1967).

22. Mason. E. E.: Gastrointestinal lesions occurring in uremia. Ann. Intern. Med.. 37: $96(1952)$. 
23. Patel, H., and Cohen. B. D.: Gas-liquid chromatographic measurement of guanidino acids. Clin. Chem., 21:838 (1975)

24. Pickford. J. C.. McGale. E. H. F., and Aber. G. M.: Studies on the metaholism of phenylalanine and tyrosine in patients with renal disease. (lin. ( him. Acta. 48: 77 (1973).

25. Ritz. E.. Krempien. B., Wanke, M.. Ziegler. M.. and Torner, U.: Clinical and experimental investigations on uremic gastritis. Verh. Dtsch. (jes. Inn. Med.. 77: $220(1971)$

26. Schultz. S. G.: Some properties and consequences of low resistance paracellular pathways across the small intestine: The advantages of being "leaky." In: M Kramer, F. Lanterbach: Intestinal Permeation. Fourth Workshop (onference Hoechst, October 19-22. 1975. p. 383 (Excerpta Medica. Amersterdam. 1977).

27. Shear, L.: Internal redistribution of tissue protein synthesis in uremia. J. Clin. Invest. 48: 1252 (1969)

28. Sherwin, R. S.. Bastal, C.. Finkelstein, F. O., Fisher, M.. Black, H., Hendler, R. and Felig. P.: Influence of uremia and hemodialysis on the turnover and metabolic effects of glucagon. J. Clin. Invest.. $57: 722$ (1976).

29. Simmons, J. M.. Wilson. C. J.. Potter. D. E.. and Holliday, M. A.: Relation of caloric deficiency to growth failure in children on hemodialysis and the growth response to calorie supplementation. N. Engl. J. Med.. 2x5: 653 (1971),

30. Soman. V.. and Felig. P.: Glucagon and insulin binding to liver membranes in a partially nephrectomized uremic rat model. J. ( lin. Invest. o(): 224 (1977).

31. Stein. I. M. Cohen, B. D.. and Kornhauser, R. S.: Guanidinosuccinic acid in renal failure experimental azotemia and inborn errors of the urea cycle. $\mathrm{N}$. Engl. J. Med.. 280: 926 (1969).

32. Streicher. $M$.: Experimental uremia-uremic enteritis. Arch. Intern. Med., 42: 835 (1928).

33. Swendseid. M. E., Wang. M., Vyhmeister. I., Chan. W., Siassi. F., and Tarn. C. F.: Amino acid metabolism in the chronically uremic rat. Clin. Nephrol.. 3: 240 (1975).

34. Wang. M.. Vyhmeister. I.. Swendseid. M. E., and Kopple. J. D.: Phenylalanine hydroxylase and tyrosine amino transferase activities in chronically uremic rats. J Nutr. 105: 122(1975)

35. Wapnir. R. A.. Exeni. R. A., McVicar, M.. and Lifshitz. F.: Experimental lead poisoning and intestinal transport of glucose. amino acids and sodium. Peditatr. Res. 11: 153 (1977)

36. Wapnir, R. A.. Hawkins, R. L., and Lifshitz, F. Hyperaminoacidemia effects on intestinal transport of related amino acids. Am. J. Physiol., 2.3: 786 (1972).

37. Wapnir. R. A., and Lifshitz. F.: 1.-Phenylalanine interactions with structurallyrelated substances at the intestinal mucosa. Biochem. Med.. 1/:370 (1974).

38. Wapnir, R. A.. and Lifshitz. F.: Absorption of amino acids in malnourished rats J. Nutr.. 1(14: 843 (1974).

39. Wizemann. V.. Ludwig. D.. Kuhl, R.. and Gurgmann. 1.: Digestive-absorptive function of the intestinal brush border in uremia: Am. J. ('lin. Nutr.. . 31: 1642 (197X).

40. Young. (i. A.. and Parsons. F. M.: Impairment of phenylalanine hydroxylation in chronic renal insufficiency. (lin. Sci. Mol. Med.. 4.5 : 89 (1973)

41. Ralston Purina Co.. St. Louis. MO.

42. BUN-TEL: Pfizer. Inc.. New York. NY

43. Harvard Instruments Co.. Millis, MA

44. New England Nuclear. Boston, MA.

45. J.T. Baker (C... Phillippsburg. NJ.

46. Sigma Technical Bulletin No. 510

47. Deceased Outober 19.1979.

48. The authors gratefully acknowledge the assistance of Drs. B. D. Cohen and H. Patel who performed the determinations of guanidinosuccinic acid in their laboratory and the technical assistance of $\mathbf{S}$. Schneider.

49. Requests for reprints should be addressed to: Melinda McVicar. M.D. Department of Pediatrics. North Shore University Hospital. Manhasset. NY 11030 (USA).

50. This research was supported in part by a grant from The Shubert Foundation and USPHS (irant I SOX RR09|2X-()|AI.

51. Received for publication June 27. 1979

52. Accepted for publication January 28.1980. 